\title{
Early Ectopic Recurrence of Craniopharyngioma in the Cerebellopontine Angle
}

\author{
Mohamad-Motaz AL MAHDI ${ }^{1}$, Joachim K. KRAUSS ${ }^{1}$, Makoto NAKAMURA ${ }^{1}$, Almuth BRANDIS ${ }^{2}$, Bujung HONG ${ }^{1}$ \\ ${ }^{1}$ Hannover Medical School, Department of Neurosurgery, Hannover, Germany \\ ${ }^{2}$ Nordstadt Hospital, Department of Pathology, Hannover, Germany \\ This case was presented in the $20^{\text {th }}$ Annual Conference of German Skullbase Society (October $9^{\text {th }}-10^{\text {th }}, 2012$ ) and in the $64^{\text {th }}$ Annual Conference of \\ German Society of Neurosurgery (May $26^{\text {th }}-29^{\text {th }}, 2013$ ).
}

\section{ABSTRACT}

Ectopic recurrence of craniopharyngioma in the cerebellopontine angle after surgical resection of a suprasellar craniopharyngioma is rare. Thus, only 5 cases were reported with a delay ranging between 4 and 26 years after removal of the primary tumor. We report a unique case of ectopic recurrence of craniopharyngioma in the cerebellopontine angle, which occurred at only 4 months after surgical resection of the primary tumor. A 24-year-old man underwent resection of a suprasellar craniopharyngioma via a right pterional approach four months earlier. During follow-up, cerebral magnetic resonance imaging (MRI) showed a round homogeneous contrast-enhancing tumor in the right cerebellopontine angle with neither relation to the internal auditory canal nor to the dura mater. After microsurgical resection, histopathological findings revealed ectopic recurrence of craniopharyngioma with similar tumors like the primary tumor. Although infrequent, craniopharyngioma may disseminate via the cerebrospinal fluid during surgical resection and grow in an ectopic place. Early follow-up and MRI scan following resection of a craniopharyngioma is recommended.

KEYWORDS: Craniopharyngioma, Ectopic recurrence, Cerebellopontine angle

\section{INTRODUCTION}

$\longrightarrow$ raniopharyngioma is a benign epithelial tumor, which arises from embryologic squamous epithelial remnants of the craniopharyngeal duct or Rathke's pouch. It is located most frequently in the sellar and suprasellar region $(1,8)$. In spite of its benign histopathological features, tumor recurrence in adjacent structures or along the surgical approach has been reported in up to $25-69 \%$ in some series with a mean time to recurrence of 1-3 years after tumor removal (5). Distant ectopic recurrence, however, has been found rarely, and when it occurs, it is usually with a delay $(2,8)$. Ectopic recurrence in the cerebellopontine angle (CPA) has been reported only exceptionally and only with a delay of at least 4 years after resection of the primary tumor in the sellar region $(2,4,5,7,8)$.
We here describe a patient with ectopic craniopharyngioma in the CPA as early as four months after resection of the primary suprasellar tumor.

\section{CASE REPORT}

A 24-year-old man underwent resection of a suprasellar craniopharyngioma via a right pterional approach four months earlier in another hospital. Histopathological findings revealed an adamantinomatous craniopharyngioma with peripheral palisading of the tumor epithelium, stellate reticulum and scattered nodules of "wet" keratin (Figure 1A-D). For treatment of secondary hypopituitarism, L-thyroxin and hydrocortisone were administered after surgery. At follow-up 4 months postoperatively, cerebral magnetic resonance imaging (MRI) showed a round homogeneous contrast-enhancing tumor in the right CPA with neither relation to the internal auditory 
canal nor to the dura mater (Figure 2A, B), which had not been present on previous imaging studies. Neither residual tumor nor local recurrence in the suprasellar region was detected at 4 months after surgery (Figure $2 \mathrm{C}$ ).

Physical examination was unremarkable. The neurological status did not show any deficits.

Microsurgical resection was performed via a lateral suboccipital approach. Intraoperatively, the tumor was yellow-reddish with a cauliflower-like appearance- No tumor infiltration of adjacent structures was detected. The histopathological findings corresponded to the previously resected adamantinomatous craniopharyngioma. The postoperative course was uneventful. The postoperative MRI revealed no recurrent tumor in the CPA (Figure 3A, B). No neurological deficit was observed. At 3-year follow-up, the patient was alive and well. Cerebral MRI showed neither evidences of recurrent tumor in the sellar region nor in the CPA.

\section{DISCUSSION}

Craniopharyngiomas are classified as grade I tumors according to the World Health Organization (WHO) classification. Nevertheless, they may adhere to or expand into contiguous neural structures, rendering them difficult to resect completely, resulting in relatively frequent recurrences.

Incomplete resection is associated with a higher rate of recurrence in the primary tumor bed or in neighbouring structures (9). Neoplastic cells that contaminate the operative field during surgery may also adhere to structures along the surgical route (e.g. implantation of craniopharyngioma along needle tracts following repeated suprasellar aspirations, sylvian fissure implantation directly adjacent to the surgical site, and craniopharyngioma recurring in the epidural space contiguous to the craniotomy site) or they may spread via the cerebrospinal fluid (CSF) and cause ectopic recurrence. Ectopic recurrence of craniopharyngioma has been reported in

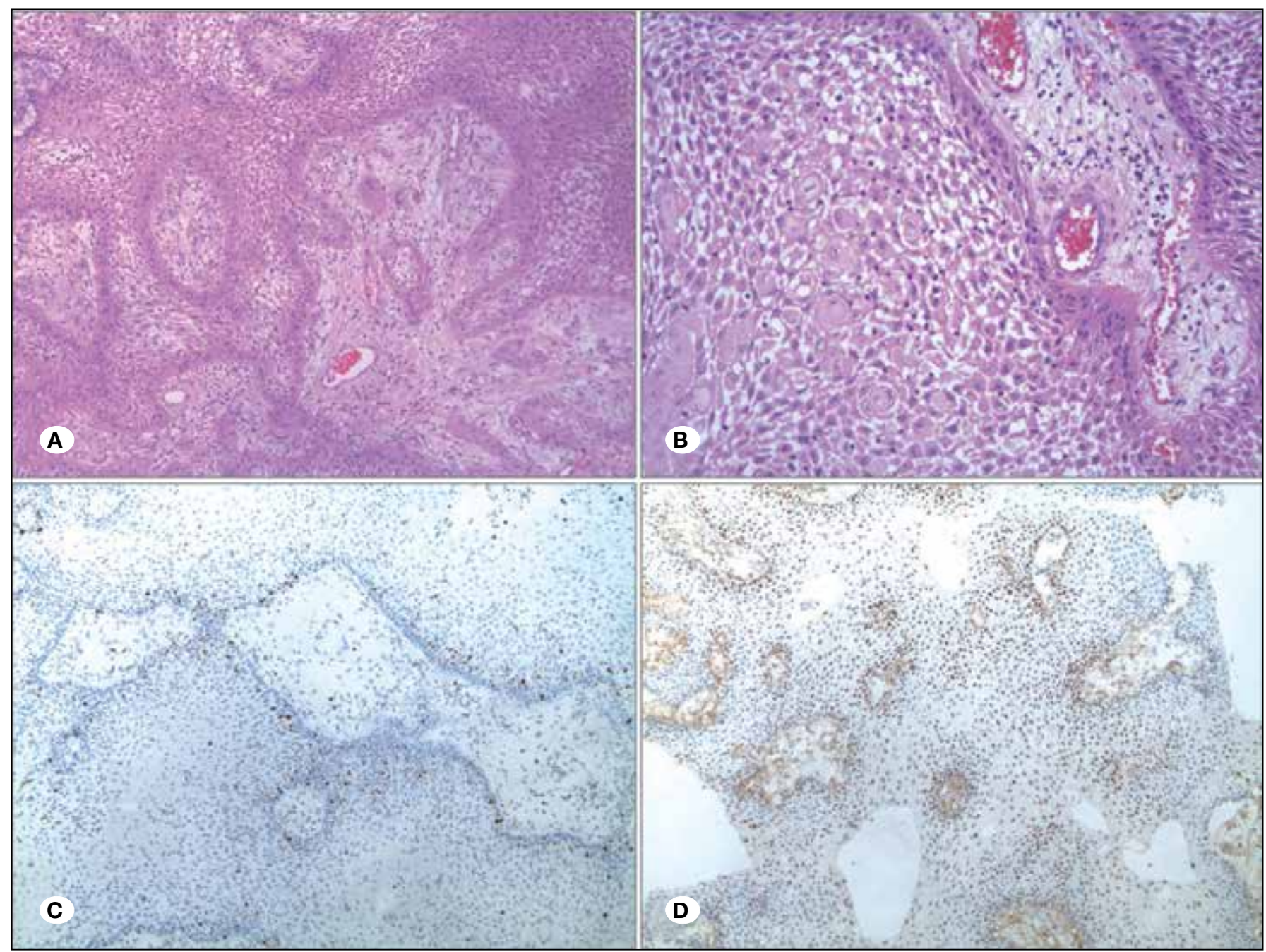

Figure 1: Histopathological examination demonstrates a craniopharyngioma with peripheral palisading of the epithelium, stellate reticulum and scattered nodules of "wet" keratin on hematoxylin and eosin staining (HE, x10 and x20) (A and B), corresponding to an adamantinomatous subtype. The proliferation rate is about $5 \%$ (MIB-1, $x 10)$ (C). About $20 \%$ of tumor cells demonstrate expression of p53 (D). 
about 44 patients thus far $(3,6)$. Such recurrences occurred in various sites including intracerebral locations, the prepontine space, the epidural space, the calvarium, and even the intradural lumbar spine $(3,6)$.

Secondary tumor manifestation in the CPA, however, has been described only in 5 cases with a delay ranging between 4-26 years (Table I) $(2,4,5,7,8)$.

Remarkably, ectopic recurrence of craniopharyngioma was discovered only incidentally in all patients described earlier. While the tumors in the reported cases were detected after years, most unusually the period after removal of the primary tumor was only four months in our patient. Treatment in all patients reported thus far was removal of the secondary tumor.
MRI is the method of choice to diagnose ectopic tumor recurrence of craniopharyngioma. The typical appearance of adamantinomatous craniopharyngiomas, e.g. lobulated contour, multiple cystic lesions, or calcification, however, might be lacking. In our case, the ectopic tumor recurrence showed a solid component with homogeneous contrast enhancement without cystic components. The lack of a relationship with the internal auditory canal or the dura mater aided in narrowing the differential diagnosis.

Treatment strategies are not well established due to the limited number of reported cases. Due to its exceptional occurrence, ectopic recurrence is often not suspected when identified on imaging. Thus, surgical resection followed with histopathological examination is advisable to confirm the diagnosis.
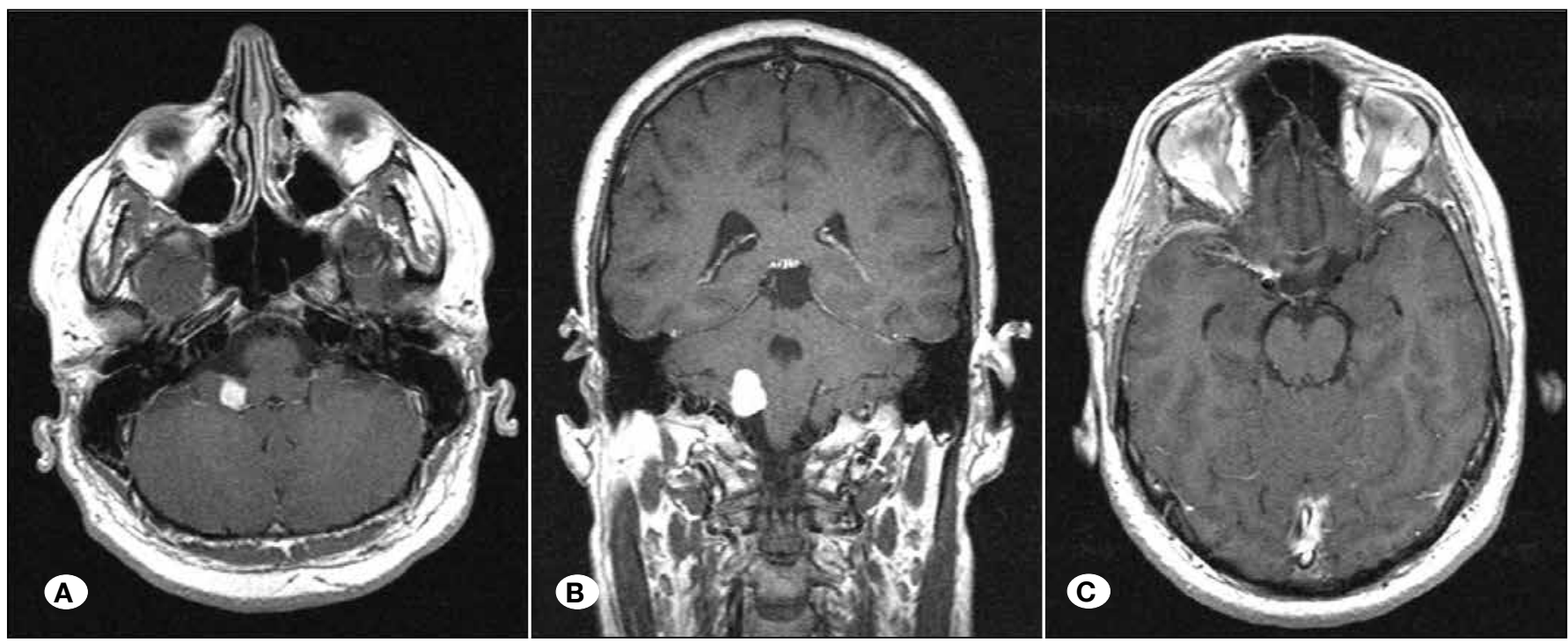

Figure 2: Axial (A) and coronal (B) T1-weighted cerebral MR images after administration of gadolinium at 4 months follow-up show a round tumor in the right cerebellopontine angle with contrast enhancement, with neither relation to the internal auditory canal nor to the dura mater. There is neither residual tumor nor local recurrence of craniopharyngioma in the suprasellar region at 4 months after surgery (C).
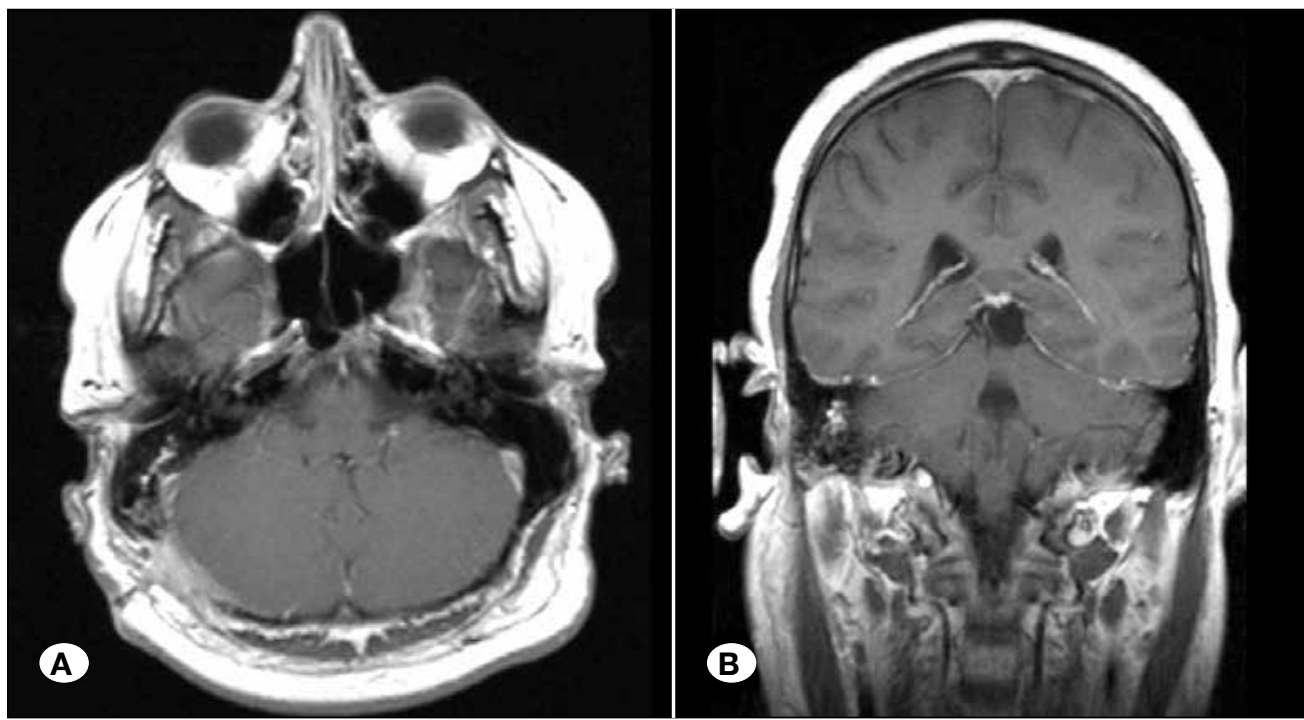

Figure 3: Axial (A) and coronal (B) T1-weighted cerebral MR images after administration of gadolinium at 6 months after surgical resection of ectopic recurrence of craniopharyngioma showed no recurrent tumor in the cerebellopontine angle. 
Table I: Literature Review of Reported Cases of Ectopic Recurrent Craniopharyngioma in the Cerebellopontine Angle

\begin{tabular}{|c|c|c|c|c|c|c|c|}
\hline Authors, year & $\begin{array}{c}\text { Age at } \\
\text { primary } \\
\text { surgery } \\
\text { (yrs), } \\
\text { sex }\end{array}$ & $\begin{array}{l}\text { Extent of } \\
\text { resection }\end{array}$ & $\begin{array}{c}\text { Surgical } \\
\text { approach }\end{array}$ & $\begin{array}{c}\text { Postoperative } \\
\text { radiotherapy }\end{array}$ & $\begin{array}{l}\text { Histopathological } \\
\text { subtype }\end{array}$ & $\begin{array}{l}\text { Side of } \\
\text { ectopic } \\
\text { recurrence }\end{array}$ & $\begin{array}{c}\text { Time to } \\
\text { detection } \\
\text { of seeding }\end{array}$ \\
\hline Tomita et al., 1992 (8) & 23 , female & subtotal & frontal right & yes & adamantinomatous & unknown & 25 years \\
\hline Bikmaz et al., 2009 (2) & 12 , male & subtotal & unknown & yes & adamantinomatous & bilateral & 12 years \\
\hline Elliot et al., 2009 (5) & 2, male & gross total & pterional right & no & adamantinomatous & left & 4 years \\
\hline De Blank et al., 2011(4) & 5 , female & gross total & pterional left & yes & unknown & left & 17 years \\
\hline Present report & 24, male & gross total & pterional right & no & adamantinomatous & right & 4 months \\
\hline
\end{tabular}

\section{- CONCLUSION}

Ectopic recurrence of craniopharyngiomas in CPA is very rare. Although ectopic recurrence tends to occur only over several years, one should always consider this possibility in the differential diagnosis if a new tumor is detected in a patient with a history of previously resected craniopharyngioma. We recommend early follow-up MRI following resection of a craniopharyngioma.

\section{REFERENCES}

1. Adamson TE, Wiestler OD, Kleihues $P$, Yasargil MG: Correlation of clinical and pathological features in surgically treated craniopharygiomas. J Neurosurg 73:12-17, 1990

2. Bikmaz K, Guerrero CA, Dammers R, Krisht AF, Husain MM: Ectopic recurrence of craniopharyngiomas: Case report. Neurosurgery 64:E382-383, 2009
3. Clark SW, Kenning TJ, Evans JJ: Recurrent ectopic craniopharyngioma in the sylvian fissure thirty years after resection through a pterional approach: A case report and review of the literature. Nagoya J Med Sci 77:297-306, 2015

4. De Blank PM, Minturn JE: A rare case of ectopic recurrence of a craniopharyngioma diagnosed 17 years after initial presentation. J Pediatr Hematol Oncol 33:392-397, 2011

5. Elliot RE, Moshel YA, Wisoff JH: Surgical treatment of ectopic recurrence of craniopharyngioma. Report of 4 cases. J Neurosurg Pediatr 4:105-112, 2009

6. Jakobs M, Orakcioglu B: Ectopic recurrent craniopharyngioma of the frontal bone. J Neurosurg 117:490-497, 2012

7. Keohane C, Hally M, Ryder DQ, Buckley TF: Late recurrence of craniopharyngioma in the cerebellopontine angle in a fertile woman. J Neurol Neurosurg Psychiatr 57:873-874, 1994

8. Tomita S, Mendoza ND, Symon L: Recurrent craniopharyngioma in the posterior fossa. Br J Neurosurg 6:587-590, 1992

9. Yasargil MG, Curcic M, Kis M, Siegenthaler G, Teddy PJ, Roth $P$ : Total removal of craniopharyngiomas. Approaches and long-term results in 144 patients. J Neurosurg 73:3-11, 1990 